\title{
Gripes asesinas y el reinado del virus corona
}

\section{Killer flus and the reign of corona virus}

\section{Gripes assassinas e o reinado do coronavírus}

\author{
Marcelo R. Ceberio, ORCID 0000-0002-4671-440X \\ Universidad de Flores. Escuela Sistémica Argentina
}

\begin{abstract}
Resumen: Este es el segundo texto de una serie de dos, que desarrollan la historia de las más grandes epidemias y pandemias del mundo. En el primero se describieron y analizaron las pandemias precedentes a la COVID-19: las pestes que asolaron el mundo greco-romano y otras enfermedades infectocontagiosas hasta llegar a la peste rosa, como fue llamado el virus del sida. El presente desarrollo se inicia con una serie de gripes mortíferas que terminan en la actualidad con la generación de los virus de la familia corona. Se describen las características de cada enfermedad y los desórdenes emocionales, económicos, psicológicos, entre otros, que se desataron en cada contexto donde proliferó el virus.
\end{abstract}

Palabras clave: COVID-19; pandemia; pobreza; gripes; emociones.

Abstract: This second text in a series of two, which unfolds the history of the largest epidemics and pandemics in the world. In the first, the pandemics preceding COVID-19 were described and analyzed: the plagues that ravaged the Greco-Roman world and other infectious contagious diseases until they reached the pink plague, as the AIDS virus was called. The present text begins with a series of deadly flus that currently end with the generation of the family of corona viruses. The text describes the characteristics of each disease and the emotional, economic, psychological disorders, among others, that were unleashed in each context where the virus proliferated.

Keywords: COVID-19; pandemic; poverty; flus; emotions.

Resumo: Este é o segundo texto de uma série de dois, que conta a história das maiores epidemias e pandemias do mundo. No primeiro artigo, foram descritas e analisadas as pandemias que antecederam a COVID-19: as pestes que assolaram o mundo greco-romano e outras doenças infectocontagiosas até chegar à peste rosa, como era chamado o vírus da AIDS. O presente texto começa com uma série de gripes mortais e termina na atualidade com a geração dos vírus corona. Foram descritas as características de cada doença e os distúrbios emocionais, econômicos, psicológicos, entre outros, que se desencadearam em cada contexto em que o vírus proliferou.

Palavras-chave: COVID-19; pandemia; pobreza; gripes; emoções.

\section{$($ (c) $)$ EY}

Esta obra está bajo una licencia de Creative Commons Reconocimiento 4.0 Internaciona 
Cómo citar:

Ceberio, M. R. (2021). Gripes asesinas y el reinado del virus corona. Ciencias Psicológicas, 15(2), e-2704. doi: https://doi.org/10.22235/cp.v15i2.2704

Correspondencia: Marcelo Rodríguez Ceberio, Universidad de Flores, Escuela Sistémica Argentina. Email:marcelorceberio@gmail.com

\section{Introducción: crisis sociales y trastornos pulmonares}

En el primer texto "Las pandemias precedentes a la COVID-19: de la peste de Atenas a la peste rosa" se exploraron las grandes pestes epidémicas del mundo antiguo, así como otras enfermedades infectocontagiosas, como la viruela, el tifus, la sífilis, la fiebre amarilla, la lepra, entre otras, hasta llegar a la peste rosa, como fue llamado el virus que genera la enfermedad del sida. De la misma manera que la historia cuenta una sucesión de pestes, tal como fueron llamadas diversas plagas que asolaron el mundo greco-romano, a partir del siglo XIX se inicia una serie de gripes mortíferas que terminan en la actualidad con la generación de los virus corona.

Notablemente, la mayoría de estas patologías de alto contagio afectan al tracto respiratorio, provocando allí y desde allí diferentes complicaciones y disfuncionalidades en el organismo. Más allá de las enfermedades orgánicas, también fueron y son graves las crisis que generaron en las sociedades que padecieron estas epidemias y pandemias, así como las secuelas psicosociológicas, emocionales, traumáticas, económicas, entre otras, que debieron enfrentar.

Si las crisis son definidas como estados de máxima tensión, situaciones que perturban la estabilidad de los sistemas (Ceberio \& Watzlawick, 2003), las pandemias realmente desorganizaron y fracturaron las sociedades en sus diferentes áreas. Pero con un factor que las agrava: fueron crisis imprevistas. Las crisis pueden ser categorizadas como esperables e imprevistas. Las esperables son aquellas que acompañan el curso de la vida de los seres humanos, como los cambios en los ciclos evolutivos, mudanzas, casamientos, muertes, nacimientos, enfermedades, etc. Las crisis imprevistas o no esperables pueden ser provocadas por enfermedades raras, muertes en hijos, secuestros, robos, epidemias, maremotos, terremotos, etc., y afectan doblemente a las sociedades, puesto que se hallan fuera del curso esperable de la vida, entonces el impacto emocional, familiar, social, económico y cognitivo es mayor (Ceberio, 2021a).

\section{Las gripes mortíferas}

La gripe española ocupa un lugar preponderante entre las pandemias y es considerada una de las peores, puesto que entre 1918 y 1920 destruyó una parte de la humanidad. Se estima que alrededor de 100 millones de personas murieron a causa de esta gripe, entre un 3 y un $6 \%$ de la población mundial de ese momento. Inclusive el número total de muertes 
civiles y militares durante la Primera Guerra Mundial fue menor que los decesos que generó esta patología (Luthy, Ritacco \& Kantor, 2018; Pané, 2020).

Cabe aclarar que el término gripe española surge a partir de que España fue uno de los países con más casos, con aproximadamente 8 millones de personas infectadas y 300.000 personas fallecidas (González García, 2013). Pero la razón por la que acabó popularizándose con ese mote es debido a una coyuntura política. Estados Unidos y Francia con numerosos casos, se hallaban en la Primera Guerra Mundial y con ello la convulsión política, social y económica hizo que se mantuviera en secreto la epidemia. España era un país neutral y tenía libertad de prensa, razón por la cual se reportó la pandemia (Organización Mundial de la Salud [OMS], 2020).

Los soldados norteamericanos que desembarcaron en Europa en abril del 1918 ya traían el virus. Una de sus particularidades era que afectaba principalmente a personas de entre 20 y 40 años, lo que resultó muy diferente a otras patologías en las que la población de riesgo son personas mayores. No existía en esa época vacuna alguna ni tratamiento con antibióticos para tratar las infecciones secundarias que podían asociarse al virus, y los esfuerzos se limitaban a cuarentenas, desinfección e higiene, así como evitar aglomeraciones de gente (Pané, 2020).

La primera pandemia de gripe A fue la llamada gripe rusa y la segunda la gripe asiática. La gripe rusa se desarrolló entre 1889 y 1890, con una tasa de morbilidad muy alta: aproximadamente el $40 \%$ de la población mundial cayó enferma. Causó un millón de muertos, especialmente personas mayores de 65 años y niños pequeños, debido a las complicaciones. El virus de la gripe A (subtipo H2N2) fue encontrado en aves y se afirma que surgió por primera vez en Rusia (Rodríguez-Maffiotte, 2018) y se extendió por tres años hasta 1892.

A posteriori, la gripe asiática -que surgió entre 1957-1958- se cobró alrededor de 1.100.000 muertes. Esta pandemia afectó especialmente a niños, adolescentes y adultos jóvenes. Sin embargo, la letalidad de la gripe asiática fue muy baja, pero al ser de rápida expansión repercutió negativamente en la economía y fue, junto a la epidemia de 1918, la que registró un número mayor de muertos en el siglo XX (Acuña, 2004; Castañeda Guillot \& Ramos Serpa, 2020).

Para algunos autores, la gripe asiática se originó a raíz de una mutación en patos salvajes que se combinó con una cepa humana preexistente. El virus se identificó por primera vez en Guizhou (China) y se propagó a Singapur, de allí a Hong Kong y luego a Estados Unidos. El rápido desarrollo de una vacuna contra el virus de la H2N2 y la disponibilidad de antibióticos para combatir infecciones secundarias que generaba limitaron que se propagase y se logró controlar la mortalidad de la epidemia. Tras 10 años de evolución, el virus de la gripe asiática desapareció, pero dio lugar a un subtipo que acabó provocando una nueva pandemia: la gripe de Hong Kong (Castañeda Guillot \& Ramos Serpa, 2020).

La llamada gripe de Hong Kong se desarrolló en entre 1968 y 1970 y provocó casi un millón de afectados. El virus que causó esta pandemia sigue en circulación en la actualidad y es considerado una de las cepas de gripes estacionales (Rodríguez-Maffiotte, 2018; Tuells, Caballero, Nolasco \& Montagud, 2012). El primer registro del brote en Hong Kong apareció el 13 de julio de 1968, y para finales del mes ya había llegado a Vietnam y Singapur. En varios meses, traída por soldados que volvían a sus hogares desde la guerra de Vietnam, llegó a la zona del canal de Panamá y Estados Unidos. 
La gripe porcina fue la segunda pandemia causada por el virus de la gripe H1N1 y fue identificada por primera vez en Estados Unidos, en abril de 2009, y se propagó rápidamente por el mundo, siendo México uno de los primeros países en detectar casos, según el Centro para la Prevención y Control de Enfermedades (CDC) de Estados Unidos (Withington, 2009). Se trata de una nueva cepa de la H1N1, que se originó cuando los virus de las gripes aviar, porcina y humana se combinaron con un virus de la gripe porcina euroasiática, razón por la que se la conoce como gripe porcina. El cuadro clínico es similar al típico de la gripe estacional, con curación espontánea, si bien el espectro clínico es extenso, pues va desde casos asintomáticos hasta neumonía grave o mortal (Rafart, Cuesta \& Agulló, 2009).

En comparación con su alta expansión (se calcula que entre el 11 y el $21 \%$ de la población fue infectada), la mortalidad no fue tan elevada. Se estima que la gripe A dejó más de 400.000 víctimas. Al menos una de cada cinco personas en el mundo resultó infectada durante el primer año de la pandemia (2009-2010) y la tasa de mortalidad fue solo del $0.02 \%$ (Salinas, 2009). Finalmente, tras 14 meses de pandemia, la OMS declaró su fin el 10 de agosto de 2010 .

\section{El reinado de los virus corona}

El coronavirus (del latín corona, que significa corona o una apariencia de halo) lleva ese nombre por la forma en que se visualiza en el microscopio electrónico. Son una familia de virus descubiertos en los años 60, de origen desconocido. En los síntomas, los diferentes tipos generan distintas enfermedades, desde un resfriado hasta una forma de neumonía grave, y casi todos poseen tratamiento, según el Consejo General de Colegios Farmacéuticos (2020). En ese sentido no revisten riesgo de muerte, más aún, la mayoría de las personas en algún momento de su vida se contagian de un coronavirus, por ejemplo, el más simple: un resfrío. Es más común el contagio en los meses de otoño o invierno, épocas de anginas, gripes, alergias y diversas infecciones respiratorias.

En la década de 1960 se describieron por primera vez en las cavidades nasales de pacientes con resfriado y solo se conocían 6 especies de coronavirus que podían infectar a humanos $(\mathrm{HCoV})$ y causar enfermedades respiratorias. Las seis son: $\mathrm{HCoV}-229 \mathrm{E}, \mathrm{HCoV}-$ OC43, HCoV-NL63, HKU1, SARS-CoV y MERS-CoV, las que, en general, provocan infecciones leves en el tracto respiratorio superior (Matoba et al., 2015; Sipulwa, Ongus, Coldren \& Bulimo, 2016; Zhang et al., 2018). Raramente pueden generar infecciones graves en población pediátrica y adultos de edad avanzada. Son endémicos a nivel global y suponen entre un 10 y un $30 \%$ de las infecciones del tracto respiratorio superior en adultos.

El SARS-CoV se inició en noviembre de 2002 en la provincia de Guangdong (China) y afectó aproximadamente a 8.096 casos en 29 países, dejando un saldo de 774 muertos. Hasta ese momento las infecciones causadas por coronavirus en humanos solo generaban infecciones leves en pacientes inmunocompetentes. La epidemia pudo ser controlada en poco tiempo y con pocas víctimas mortales, sin llegar a una multiplicación de contagio grave (Sampathkumar, Temesgen, Smith \& Thompson, 2003). Se define como una clase de neumonía grave y los síntomas consisten en fiebre superior a los 38 grados, dificultades respiratorias y otros síntomas como escalofríos, mialgias, cefaleas y malestar general (Castro-Sansores \& Góngora-Biachi, 2003). La mortalidad del SARS-CoV se ha cifrado en 
el $10 \%$ aproximadamente (Sampathkumar et al., 2003). Desde el 2004, no se han registrado casos de SARS-CoV.

Diez años después, en el año 2012, emergió otro coronavirus altamente patógeno, identificado por primera vez en Arabia Saudita: el coronavirus causante del síndrome respiratorio de Oriente Medio (MERS-CoV, por su sigla en inglés). El primer fue un hombre de dicho país, con 60 años, que padecía una neumonía aguda y murió de insuficiencia renal. La dinámica del virus evolucionó y fueron reportados los primeros casos en Inglaterra (Valentín, Montero \& Florentini, 2020), Alemania y en varios países de Medio Oriente (Bratanich, 2015).

Hasta octubre de 2019 se han notificado más de 2.400 casos en distintos países, con una letalidad del $35 \%$. En la sintomatología se observan graves problemas respiratorios, además de fiebre, tos y dificultad para respirar, aunque en un primer momento puede ser asintomático (Castro-Sansores \& Góngora-Biachi, 2003). En los casos más graves también se producen vómitos, diarrea e incluso expectoración con sangre. Desde la aparición del SARS se han descubierto un gran número de coronavirus en murciélagos, que sirven como huésped. Es probable que los camellos sean un importante reservorio para este tipo de coronavirus y una fuente animal de infección en los seres humanos, como especificaba la OMS (2020; ECDC, 2020).

\section{La corona actual: la COVID-19}

La historia inicia en la provincia de Hubei en Wuhan (China) en diciembre del 2019, con un grupo de pacientes con diagnósticos de neumonía de origen desconocido. La mayoría de ellos fueron vinculados epidemiológicamente a un mercado mayorista de pescados, mariscos y animales vivos y no procesados en la provincia de Hubei. Un alto consumo de proteína animal, incluyendo animales exóticos, como culebras y murciélagos, sumado a normas de higiene deficientes en los mercados de alimentos, han posibilitado desarrollar lo que se denomina zoonosis, que es la transmisión de virus entre animales y desde animales a humanos (Ahmad et al, 2020; Mackenzie \& Smith, 2020).

A mediados de diciembre de 2019 se reportaron los primeros casos que fueron hospitalizados al presentar síntomas de distrés respiratorio agudo. La mayoría de los pacientes dijeron tener relación directa o indirecta con el mercado citado, que fue clausurado en enero de 2020. Días después, los investigadores chinos anunciaron que habían identificado un nuevo tipo de coronavirus (nuevo coronavirus, 2019-nCoV), siendo descartados otros patógenos, como el SARS-CoV, el MERS-CoV, el virus de la gripe, la gripe aviar y el adenovirus. En esos inicios, la crisis china por los niveles de contagio empezó a difundir lo que estaba sucediendo y los casos iban en aumento (Ramos, 2020), haciéndose más difícil seguir el rastreo. Se le asignó a la enfermedad el nombre de COVID-19-inicialmente novel coronavirus (2019-nCoV)- y se pensó erróneamente que no era altamente contagioso, ya que no había registro de infección persona-persona.

Después de 10 días, había numerosos casos reportados (571) en 25 provincias de China. A partir de ahí, el número de pacientes contagiados fue aumentando exponencialmente en China continental y en diferentes países, incluyendo Vietnam, Taiwán, Tailandia, Sri Lanka, Camboya, Japón, Malasia, Singapur, República de Corea, Nepal, Emiratos Árabes Unidos, Filipinas, India, Irán, Canadá, Estados Unidos, Finlandia, Francia, 
España, Australia y Alemania (Pulcha Ugarte, Pizarro-Lau, Gastelo-Acosta \& MaguiñaVargas, 2020).

El primer reporte de caso en el continente americano surgió el 19 de enero de 2020 en el estado de Washington (Estados Unidos). Asimismo, el 24 de enero se reporta el primer caso de COVID-19 en Europa, específicamente en Burdeos (Francia), que había visitado China recientemente. El 26 de febrero de 2020, el Ministerio de Salud de Brasil reporta el primer caso de COVID-19 en Sudamérica. El 11 de marzo, con 118.000 casos reportados en 114 países y casi 4.300 personas fallecidas, la Organización Mundial de la Salud declara que el brote de la enfermedad del coronavirus causado por el SARS-CoV2 es considerada una pandemia y de "emergencia pública de interés internacional", a partir del diagnóstico de un grupo de expertos y lineamientos sanitarios (Pulcha Ugarte et al., 2020; OMS, 2020).

\section{Síntomas y medidas preventivas}

La COVID-19 se registra tanto en personas mayores como en aquellos individuos con inmunodepresión o con enfermedades crónicas como diabetes, obesidad, algunos tipos de cáncer o enfermedad pulmonar crónica. En los casos más graves pueden ocasionar insuficiencia respiratoria. En la pandemia se ha constatado que en torno al $80 \%$ de las personas infectadas presentan síntomas leves o son asintomáticas. Los signos clínicos más comunes incluyen los propios de un resfriado común: fiebre, tos y síntomas respiratorios (disnea y otras alteraciones de la respiración). También se han notificado síntomas gastrointestinales, incluyendo diarrea (Rodríguez-Morales et al., 2020). En los casos más severos, la infección puede causar bronquitis o neumonía (bien sea neumonía viral directa o favorecer una bacteriana secundaria), síndrome respiratorio agudo severo, fallo o insuficiencia renal e incluso la muerte (Eliezer et al., 2020).

Con el fin de frenar y prevenir el contagio se tomaron una serie de medidas, como el aislamiento, el control de la temperatura con cámaras térmicas y termómetros digitales, la higiene de manos y de la casa, el distanciamiento de 2 metros entre las personas, el uso de barbijos o mascarillas, entre otras. A medida que ha ido evolucionando la pandemia se han incorporado nuevas formas de detección, diagnóstico y pronóstico de la enfermedad (BBC, 2020).

\section{Conclusión}

Casi todas las epidemias y pandemias de la historia han afectado a los países menos desarrollados y con mayores niveles de inestabilidad económica. Esto quiere decir que países con menores posibilidades económicas y mayores índices de pobreza conllevan a un déficit de la estructura sociosanitaria, sumado a niveles de cultura paupérrimos, formándose así una ecuación que tiende a producir mayor labilidad al contagio y menor estructura hospitalaria edilicia y profesional para abordar la atención (Cortés, 2006; Klinger, 1989; Marchiori Buss, 2006; Salinas, 2009; Wagstaff, 2002).

Hay una fuerte asociación entre inequidad en los ingresos, salud y bajo capital social (Cortés, 2006). La ausencia de camas e insumos médicos en los hospitales, aparatología moderna deficiente, ineficaz conducta poblacional y anomia hacia las formas de evitación del contagio son algunos de los tópicos que obturan la salud y la anulación de la progresión epidémica. Entonces, ¿qué pasa después de una pandemia?: puede haber predictores, pero 
cada contexto obrará de acuerdo a los parámetros que le imponen la experiencia, sus creencias, los valores, el nivel socioeconómico, las políticas sanitarias, el nivel sociocultural, entre otros factores.

La pandemia de la COVID-19 es una crisis y como tal no puede pasar inadvertida por una sociedad. Resulta imposible actuar desde la negación, la crisis conlleva al estrés. Los mecanismos del estrés crónico hacen que se debilite el sistema inmunitario y acreciente la posibilidad de contagio (Camps, Sánchez \& Sirera, 2006; Chacón \& López, 1994). Este estrés se halla potenciado de cara a la emergencia de emociones comunes, como las que se observa en el contexto actual: incertidumbre, ansiedad/angustia y miedo (Ceberio 2021a; 2021b). Esta tríada emocional es absolutamente lógica (si es que hay una lógica de reacción emocional).

En la revisión histórica se observa que cada pandemia se instauró en cada contexto de manera firme y cuanto más atrás en el tiempo menores eran los recursos médicos y sociales para revertir la situación. Sin embargo, a pesar de los escasos recursos, la humanidad desarrolló posibilidades, las puso en juego y creó oportunidades para restaurar la salud. Cada pandemia dejó como saldo un gran aprendizaje, en algunas épocas con mayor toma de consciencia que en otras.

Todas las pandemias que se desarrollaron en el texto muestran la reproducción geométrica y abrupta del contagio de la enfermedad. Cada epidemia o brote virósico importante muestra las peculiaridades de los contextos, tales como pobreza, falta de higiene, descuido, ritmo hipercinético y estresante con que se vive la vida, entre otros factores. Esta situación pone sobre el tapete el efecto mariposa (el batir de alas de una mariposa en un extremo del planeta puede generar por efecto dominó un huracán en otra parte), señalado por E. Norton Lorenz, que forma parte de la teoría del caos (Briggs \& Peat, 2005; Cazau, 1995). Este ejemplo, que proviene de un proverbio, alude a una visión holística, en la que todos los acontecimientos del universo se hallan en relación e indefectiblemente repercuten los unos en los otros y viceversa, pero sin implicar necesariamente una repercusión de enorme magnitud a partir de acontecimientos ínfimos. Los grandes eventos pueden ser el resultado de una cadena de sucesos mínimos o no, pero también los macros repercuten en los pequeños hechos. En síntesis, toda una complejidad imposible de describir.

En ese sentido, la emergencia de esta crisis pandémica descubre esta perspectiva sistémica donde todas las personas están involucradas en mayor o menor medida, puesto que forman parte activa de una dinámica ecológica y esto las hace en parte responsables de cada cosa que suceda. Este modelo epistemológico de pensar el contexto y la vida se riñe con el "virus del individualismo", que aparece en numerosas personas que operan bajo la política del egoísmo, por ejemplo, con actitudes segregacionistas. Muchas personas con temor al contagio, rayando la paranoia, marginan a personas que se contagiaron o el personal de la salud por hallarse en contacto con los enfermos, de la misma manera que se segregó a los enfermos de sida, a los sifilíticos o a los leprosos en otras pandemias (Miranda, 2021). En los inicios de la aparición de la COVID-19, hubo fuertes actitudes xenófobas, principalmente hacia las personas asiáticas, como muestran algunas investigaciones (Aleixandre-Benavent, Castelló-Cogollos \& Valderrama-Zurián, 2020; Bautista, 2020).

Cada pandemia activa los fundamentos de la solidaridad, aunque, de acuerdo al mundo actual, no se puede estar muy seguro de realizar tal afirmación. La vulnerabilidad y la resiliencia son construcciones que han tomado sentido en cada una de las epidemias, 
delimitando un contexto que va de la estabilidad a la inestabilidad y, por ende, al cambio. Por lo tanto, cada persona desarrolla diferentes acciones a partir de los distintos significados que le atribuya a los hechos que irrumpan en su contexto.

\section{Referencias}

Acuña, L. (2004). Influenza: Historia y amenazas. Revista chilena de infectología, 21(2), 162-164. doi: https://doi.org/10.4067/s0716-10182004000200012

Ahmad, T., Khan, M., Haroon, T. H. M., Nasir, S., Hui, J., Bonilla-Aldana, D. K., \& Rodriguez-Morales, A. J. (2020). COVID-19: Zoonotic aspects. Travel Medicine and Infectious Disease, 36, 101607. doi: https://doi.org/10.1016/j.tmaid.2020.101607

Aleixandre-Benavent, R., Castelló-Cogollos, L., \& Valderrama-Zurián, J. C. (2020). Información y comunicación durante los primeros meses de Covid-19. Infodemia, desinformación y papel de los profesionales de la información. El profesional de la información (EPI), 29(4). doi: https://doi.org/10.3145/epi.2020.jul.08

Bautista, F. J. (2020). Paz vulnerable: pandemias, Covid-19 y racismo. Revista de Cultura de paz, 4, 13-32.

BBC. (12 marzo de 2020). Coronavirus: las pandemias que pusieron al mundo en alerta en la historia reciente (y cómo se afrontaron). BBC. Recuperado de https://www.bbc.com/mundo/noticias-51843449

Bratanich, A. (2015). MERS-CoV: transmisión y el papel de nuevas especies hospederas. Revista Argentina de Microbiología, 47(4), 279. doi: https://doi.org/10.1016/j.ram.2015.11.001

Briggs, J. \& Peat, F. D. (2005). Espejo y reflejo: del caos al orden. Guía ilustrada de la teoría del caos y de la ciencia de la totalidad. Editorial Gedisa.

Camps, C., Sánchez, P. T., \& Sirera, R. (2006). Inmunología, estrés, depresión y cáncer. Psicooncología, 3(1), 35-48.

Castañeda Guillot, C. C. \& Ramos Serpa, G. (2020). Principales pandemias en la historia de la humanidad. Revista Cubana de Pediatría, 92(supl.1), e1183.

Castro-Sansores, C. J. \& Góngora-Biachi, R. A. (2003). Síndrome Respiratorio Agudo Severo: la primera epidemia del siglo XXI. Revista Biomédica, 14(2), 89-100. doi: https://doi.org/10.32776/revbiomed.v14i2.346

Cazau, P. (1995). La teoría del caos. Recuperado de http://galeon. com/pcazau/artfis_caos

Ceberio M. R. \& Watzlawick P. (2003) La construcción del universo. Herder.

Ceberio, M. R. (2021a). Contexto y vulnerabilidad en la crisis del covid-19: emociones y situaciones del durante e interrogantes acerca del después. Revista Ajayu, 19(1), 90126.

Ceberio, M. R. (2021b). Psicólogos en el frente: la atención durante la crisis del Covid-19. De las emociones tóxicas a la salud psicológica. Archivos de Medicina (Manizales), 21(1), 225-237. doi: https://doi.org/10.30554/archmed.21.1.3941.2021

Centro Europeo para la Prevención y el Control de Enfermedades [ECDC]. (2020). COVID 19. Situations updates. Recuperado de https://www.ecdc.europa.eu/en/covid-19

Consejo General de Colegios Farmacéuticos. (2020). Informe técnico coronavirus: COVID19. Madrid: Consejo General de Colegios Farmacéuticos.

Cortés, A. (2006). Inequidad, pobreza y salud. Colombia Médica, 37(3), 223-227. 
Chacón, S. C., \& López, H. S. (1994). ¿Es el estrés el que controla la respuesta inmune o viceversa? Veterinaria México, 25(2), 99-103.

Eliezer, M., Hautefort, C., Hamel, A. L., Verillaud, B., Herman, P., Houdart, E., \& Eloit, C. (2020). Sudden and complete olfactory loss of function as a possible symptom of COVID-19. JAMA otolaryngology-head \& neck surgery, 146(7), 674-675. doi: https://doi.org/10.1001/jamaoto.2020.0832

González García, A. (2013). Avances y tendencias actuales en el estudio de la pandemia de gripe de 1918-1919. Vínculos de Historia, (2), 309-330.

Klinger, I. (1989). Pobreza y salud: reflexiones sobre América Latina. Boletín de la Oficina Sanitaria Panamericana (OSP), 107(5).

Luthy, I. A., Ritacco, G. V., \& Kantor, I. K. (2018). A cien años de la gripe española. Medicina (Buenos Aires), 78(2), 113-118.

Mackenzie, J. S., \& Smith, D. W. (2020). COVID-19: a novel zoonotic disease caused by a coronavirus from China: what we know and what we don't. Microbiology Australia, 41(1), 45-50. doi: https://doi.org/10.1071/ma20013

Marchiori Buss, P. (2006). Globalización, pobreza y salud: premio conferencia Hugh Rodman Leavell. Salud colectiva, 2(3), 281-297. doi: https://doi.org/10.18294/sc.2006.73

Matoba, Y., Abiko, C., Ikeda, T., Aoki, Y., Suzuki, Y., Yahagi, K., ... \& Mizuta, K. (2015). Detection of the human coronavirus 229E, HKU1, NL63, and OC43 between 2010 and 2013 in Yamagata, Japan. Japanese journal of infectious diseases, 68(2), 138141. doi: https://doi.org/10.7883/yoken.jjid.2014.266

Miranda, F. (2021). Pandemias e história na era da COVID-19. Medievalista, 29, 411-418. doi: https://doi.org/10.4000/medievalista.4008

Organización Mundial de la Salud [OMS]. (2020). Coronavirus disease (COVID-19) pandemic. Recuperado de https://www.who.int/emergencies/diseases/novelcoronavirus-2019

Pané, G. (25 de marzo de 2020). Grandes pandemias de la historia. Historia: National Geographic. Recuperado de https://historia.nationalgeographic.com.es/a/grandespandemias-historia_15178

Pulcha-Ugarte, R., Pizarro-Lau, M., Gastelo-Acosta, R., \& Maguiña-Vargas, C. (2020). ¿Qué lecciones nos dejará el covid-19?: Historia de los nuevos coronavirus. Revista de la Sociedad Peruana de Medicina Interna, 33(2), 68-76. doi: https://doi.org/10.36393/spmi.v33i2.523

Rafart, J. V., Cuesta, J. G., \& Agulló, M. B. (2009). Principales características de la pandemia por el nuevo virus influenza A (H1N1). Medicina Clínica, 133(13), 513-521. doi: https://doi.org/10.1016/j.medcli.2009.09.002

Ramos, C. (2020). Covid-19: la nueva enfermedad causada por un coronavirus. Salud Pública de México, 62(2, Mar-Abr), 225-227.

Rodríguez-Maffiotte, M. (2018). La gripe en la historia. Ars Clínica y Académica, 4(3).

Rodríguez-Morales, A. J., Sánchez-Duque, J. A., Hernández Botero, S., Pérez-Díaz, C. E., Villamil-Gómez, W. E., Méndez, C. A., \& Balbin-Ramon, G. J. (2020). Preparación y control de la enfermedad por coronavirus 2019 (COVID-19) en América Latina. Acta Medica Peruana, 37(1), 3-7. 
Salinas, P. J. (2009). La influenza o gripe porcina AH1N1 de la infección hasta el tratamiento. MedULA, 18(1), 4-8.

Sampathkumar, P., Temesgen, Z., Smith, T. F., \& Thompson, R. L. (2003). SARS: epidemiology, clinical presentation, management, and infection control measures. Mayo Clinic Proceedings, 78(7), 882-890. doi: https://doi.org/10.4065/78.7.882

Sipulwa, L. A., Ongus, J. R., Coldren, R. L., \& Bulimo, W. D. (2016). Molecular characterization of human coronaviruses and their circulation dynamics in Kenya, 2009-2012. Virology journal, 13(1), 1-9. doi: https://doi.org/10.1186/s12985-0160474-X

Tuells, J., Caballero, P., Nolasco, A., \& Montagud, E. (2012). Factores asociados a la predisposición a vacunarse contra la gripe pandémica $\mathrm{A} / \mathrm{H} 1 \mathrm{~N} 1$ en población adulta del Departamento de Salud de Elche (España): influencia de las fuentes de información. Anales del Sistema Sanitario de Navarra, 35(2), 251-260. doi: https://doi.org/10.4321/s1137-66272012000200007

Valentín, E. L., Montero, J. S. N., \& Florentini, M. G. Q. (2020). Coronavirus causante del síndrome respiratorio de Oriente Medio (MERS-CoV). Revista Médica Carriónica, 1(1).

Wagstaff, A. (2002). Pobreza y desigualdades en el sector de la salud. Revista panamericana de salud pública, 11, 316-326. doi: https://doi.org/10.1590/s102049892002000500007

Withington, J. (2009). Historia mundial de los desastres crónicas de guerras, terremotos, inundaciones y epidemias. Madrid: Turner Publicaciones.

Zhang, S. F., Tuo, J. L., Huang, X. B., Zhu, X., Zhang, D. M., Zhou, K., ... \& Li, M. F. (2018). Epidemiology characteristics of human coronaviruses in patients with respiratory infection symptoms and phylogenetic analysis of $\mathrm{HCoV}-\mathrm{OC} 43$ during 2010-2015 in Guangzhou. Plos one, 13(1), e0191789. doi: https://doi.org/10.1371/journal.pone.0191789

Contribución de los autores: a) Concepción y diseño del trabajo; b) Adquisición de datos; c) Análisis e interpretación de datos; d) Redacción del manuscrito; e) revisión crítica del manuscrito.

M. R. C. ha contribuido en a, b, c, d, e.

Editora científica responsable: Dra. Cecilia Cracco. 